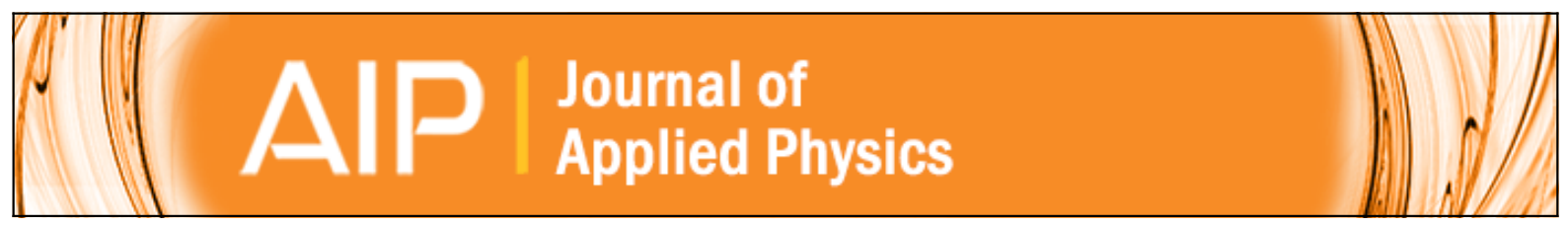

The influence of tin implantation on the oxidation of iron

I. J. R. Baumvol

Citation: Journal of Applied Physics 52, 4583 (1981); doi: 10.1063/1.329334

View online: http://dx.doi.org/10.1063/1.329334

View Table of Contents: http://scitation.aip.org/content/aip/journal/jap/52/7?ver=pdfcov

Published by the AIP Publishing

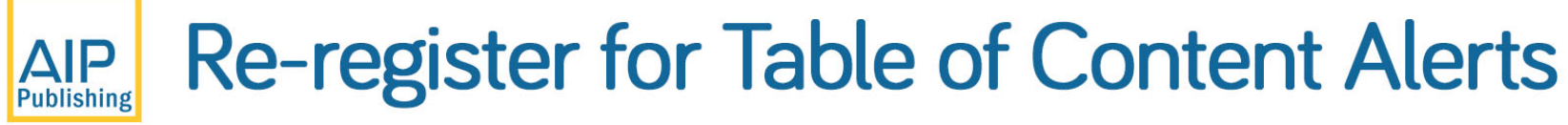

Create a profile.

Sign up today! 


\title{
The influence of tin implantation on the oxidation of iron
}

\author{
I. J. R. Baumvol \\ Instituto de Física, Universidade Federal do Rio Grande do Sul 90000 Porto Alegre, RS, Brasil
}

(Received 20 November 1980; accepted for publication 26 March 1981)

The high-temperature oxidation of metallic iron implanted with Sn ions at doses between $5 \times 10^{15}$ and $5 \times 10^{16} \mathrm{Sn}$ ions $\mathrm{cm}^{-2}$ is studied in the temperature range from 300 to $500^{\circ} \mathrm{C}$. Ion implantation of $\mathrm{Sn}$ reduces the oxidation rate constant of iron up to a factor of 10 at all experimental temperatures. The mechanisms that underlie this process are investigated using physical techniques such as Rutherford backscattering of ${ }^{4} \mathrm{He}$ particles, conversion electron Mössbauer scattering of ${ }^{57} \mathrm{Fe}$ and ${ }^{119} \mathrm{Sn}$ and scanning electron microscopy to analyze the surface of the implanted and oxidized samples. The FeSn ${ }_{2}$ intermetallic phase was formed in the sample implanted at room temperature. This compound is partially decomposed to the FeSn intermetallic and free $\mathrm{Sn}$ in solution in iron when the implanted sample is oxidized at $500^{\circ} \mathrm{C}$. Ion implantation produces a surface composition very similar to that obtained with the more conventional methods of tinplating. The observed inhibition of the corrosion is discussed on the basis of this similarity.

PACS numbers: $61.70 . T \mathrm{~m}, 82.30 .-\mathrm{b}$

\section{INTRODUCTION}

Surface ion implantation of different atomic species is capable of modifying the behavior of many metals and alloys in both high-temperature oxidation and aqueous corrosion. The beneficial effects include reduction of the oxidation rate constant, modification of the time dependence of the reaction kinetics, and improvement of the adherence of the oxide layer. ${ }^{1-3}$ The method is being considered for corrosion protection and for the protection of metals against oxidative wear. ${ }^{4.5}$

In view of such a wide range of potential applications of ion implantation as a reliable, interface-free, protective treatment for the surface of materials, many questions have emerged concerning the physical mechanisms by which this protection against corrosion is obtained. In some cases, the main mechanism may be the formation of a flat oxide film of the implanted material ${ }^{1,3}$ or the formation of double oxides of the implanted and substrate elements ${ }^{2}$ or even other physical phenomena such as the decoration of grain boundaries by the implanted species to block the routes for ion migration.

In this work the oxidation of pure iron implanted with $\mathrm{Sn}^{+}$ions at different doses $\left(5 \times 10^{15}-5 \times 10^{16} \mathrm{Sn}^{+} \mathrm{cm}^{-2}\right)$ was studied for the temperature range $300-500^{\circ} \mathrm{C}$. One of the motivations of this work was to compare the mechanism by which Sn ion implantation inhibits the oxidation with that mechanism which acts in the case of tinplating.

As a second reason for investigating the high-temperature oxidation of this system, the implantation of $\mathrm{Sn}^{+}$ions also greatly reduces the wear rate of pure iron as measured on a pin-on-disc machine. ${ }^{4}$ From the work of Kerridge, ${ }^{6}$ the factor determining the wear rate is considered to be the rate of oxidation of the rubbing surfaces and of the transferred material before it is removed. The high temperatures developed at the localized contact regions, or asperities, cause the transferred material to become oxidized and the oxide, not being strongly adherent, is rubbed off by repeated sliding. Since the implantation of tin considerably reduces the oxida- tion rate of iron, this seems to be one of the reasons for the reduction in wear. ${ }^{4}$ To strengthen this interpretation for the beneficial effect of the implantation of $\mathrm{Sn}^{+}$ions in iron, it is necessary to have a detailed knowledge of the oxidation kinetics and mechanism.

The oxidation kinetics of the implanted samples were determined for different temperatures and doses of implantation. Analytical techniques have been used to investigate the physicochemical behavior of the system during oxidation. These techniques include Rutherford backscattering (RBS) of $2 \mathrm{MeV}^{4} \mathrm{He}$ particles, conversion electron Mössbauer scattering (CEMS) of ${ }^{57} \mathrm{Fe}$ and ${ }^{119} \mathrm{Sn}$, and scanning electron microscopy (SEM). The results of these investigations are discussed and compared with the existing literature for the $\mathrm{Fe}-\mathrm{Sn}$ system and for the tinplating processes.

\section{EXPERIMENTAL MATERIALS, PROCEDURES, AND RESULTS}

\section{A. Sample preparation and oxidation kinetics measurements}

Pure iron foils from Goodfellow Metals $(99.99+\%)$ were electropolished in an electrolytic solution of $35 \%$ perchloric acid, $63 \%$ acetic anhydride, $2 \% \mathrm{H}_{2} \mathrm{O}$ at $250 \mathrm{~mA}$ $\mathrm{cm}^{-2}$ and then annealed in vacuum at $800^{\circ} \mathrm{C}$ for $1 \mathrm{~h}$ at $10^{-7}$ Torr.

These samples were implanted with $\mathrm{Sn}^{+}$ions at 200 $\mathrm{keV}$ in the Harwell 500-keV Cockcroft-Walton ion implanter. The temperature of the samples was always kept below $200^{\circ} \mathrm{C}$. The implantation doses were between $5 \times 10^{15}$ and $5 \times 10^{16} \mathrm{Sn}$ ions $\mathrm{cm}^{-2}$. The samples for CEMS experiments were implanted with ${ }^{119} \mathrm{Sn}^{+}$in the $200-\mathrm{keV}$ Lintott facility at Harwell.

All the samples were oxidized isothermally in a furnace with a constant flow of $11 \mathrm{~m}^{-1}$ of dry oxygen at temperatures ranging from 300 to $500^{\circ} \mathrm{C}$. The analyses of the oxide film were performed by measuring the total amount of oxygen in the sample by means of the ${ }^{16} \mathrm{O}\left(d, p_{1}\right)^{17} \mathrm{O}^{*}$ nuclear reaction at $880 \mathrm{keV} .{ }^{7}$ The deuteron beam was produced in the 6- 


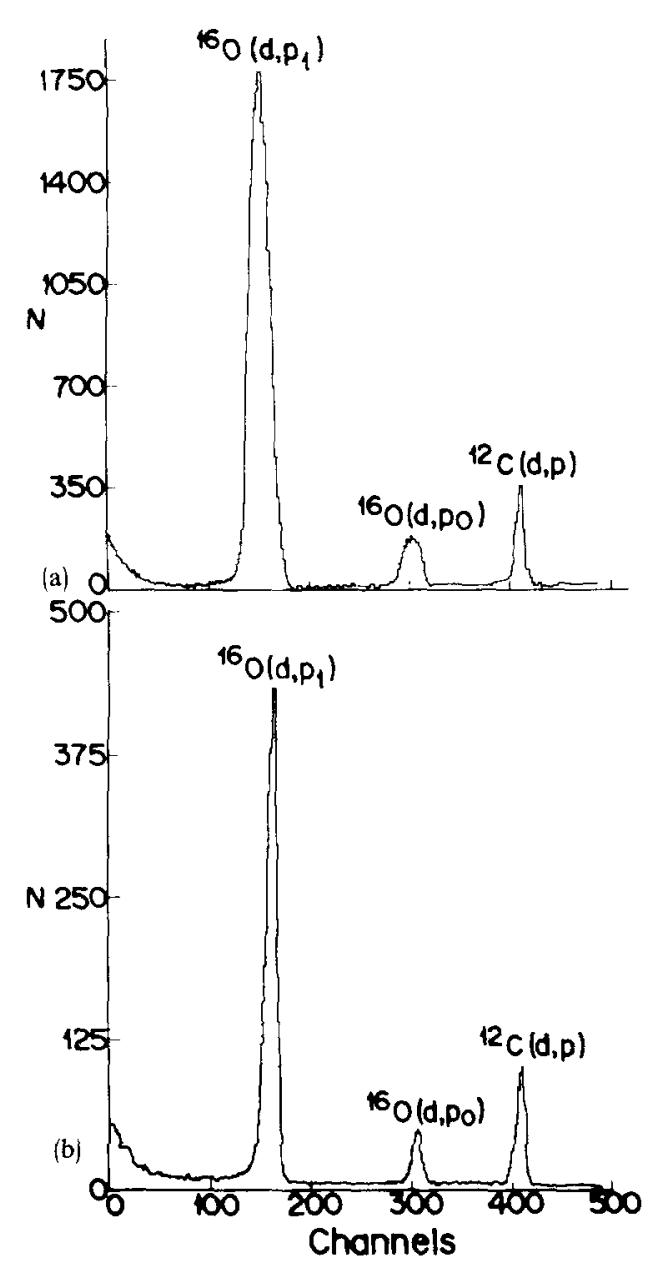

FIG. 1. Particle spectra for the nuclear reaction ${ }^{16} \mathrm{O}\left(d, p_{1}\right)$ in unimplanted $(\mathrm{a})$ and implanted $\left(5 \times 10^{16} \mathrm{Sn}^{+}\right.$ions $\left.\mathrm{cm}^{-2}\right)$ (b) pure iron samples oxidized at $500^{\circ} \mathrm{C}$ for $20 \mathrm{~min}$.

$\mathrm{MeV}$ Van de Graff at Harwell and the protons $\left(p_{1}\right)$ from the nuclear reaction were detected by a surface barrier silicon detector at $160^{\circ}$ to the incident beam. In Fig. 1 are shown typical spectra for this nuclear reaction in unimplanted and implanted pure iron samples exposed to oxygen at $500^{\circ} \mathrm{C}$ for 20 min.

The amount of oxygen taken up by the samples is determined by calibrating the nuclear reaction results against an anodically grown $\mathrm{Ta}_{2} \mathrm{O}_{5}$ standard. The weight-gain values for the unimplanted samples agree very well with the values obtained by gravimetric methods. ${ }^{89}$ The limitation of oxidation times up to $80 \mathrm{~min}$ was not a major limitation on the validity of the results, because the mechanisms by which the implanted species acts as an oxidation inhibitor is supposed to be established in the early stages of the sample exposure. Besides, the main characteristics of the oxidation kinetics of iron are well established after $1 \mathrm{~h}$ of exposure to oxygen at high temperatures. ${ }^{8}$

A plot of oxidation kinetics for unimplanted and $\mathrm{Sn}^{+}$. implanted iron is given in Fig. 2. The parabolic growth law for the oxide film thickness, $\chi^{2}=K_{p} t,^{10,11}$ is confirmed for pure iron at all temperatures; it is also very reasonably fitted by the data for the implanted samples. Figure 2 reveals the strong reduction of the oxidation rate constant $K_{p}$ for sam-

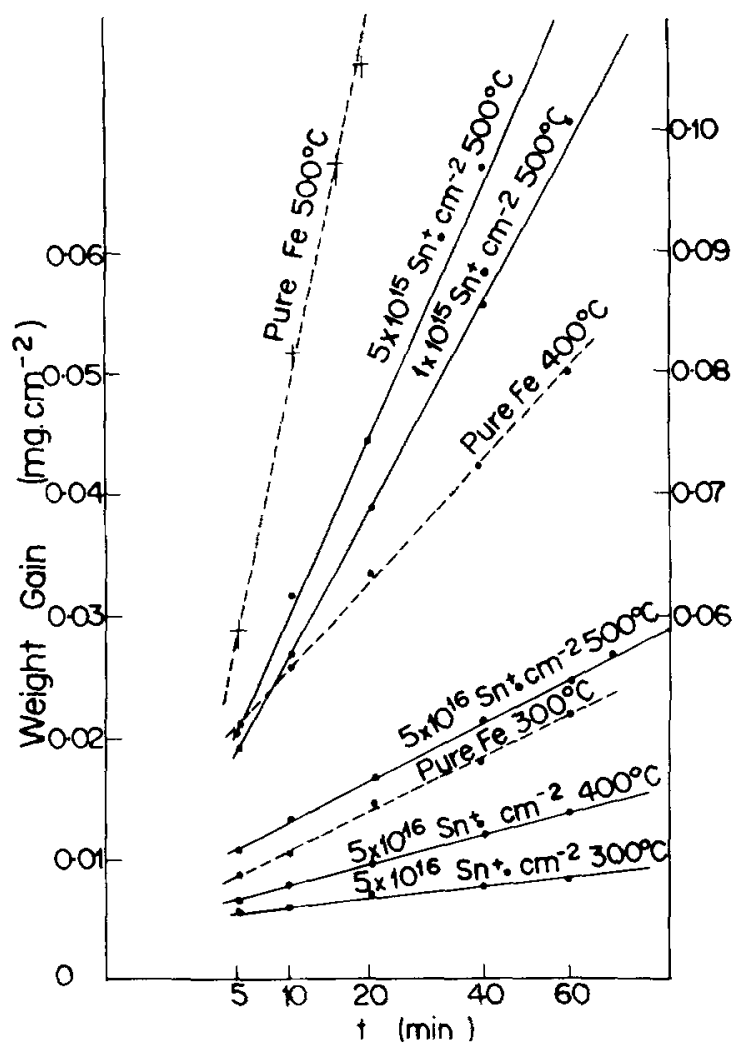

FIG. 2. Oxidation kinetics of unimplanted and $\mathrm{Sn}^{+}$-implanted pure iron. The experimental points for unimplanted iron oxidized at $500^{\circ} \mathrm{C}$ refer to the vertical scale on the right-hand side of the figure.

ples implanted with $5 \times 10^{16} \mathrm{Sn}$ ions $\mathrm{cm}^{-2}$ and also a smaller effect for lower-dose implantations. Table I displays the values of $K_{p}$ for the different samples; $K_{p}$ values for the unimplanted samples are in good agreement with the values quoted in the literature. $^{12}$

\section{B. Analytical techniques results}

The reduction in the oxidation rate of iron due to ion implantation with $\mathrm{Sn}^{+}$ions certainly results from the inhibition of the main mechanism for the growth of the oxide scale, namely, the outward diffusion of iron cations through the scale. Analytical techniques were used to investigate the inhibition of this solid-state diffusion process.

TABLE I. Oxidation rate constants $K_{p}$ for unimplanted and $\mathrm{Sn}^{+}$implanted, pure iron samples.

\begin{tabular}{lll}
\hline & $\begin{array}{l}\text { Implantation dose } \\
\left(\text { Sn ions } \mathrm{cm}^{-2}\right)\end{array}$ & $\begin{array}{l}K_{p} \\
\left(\mathrm{mg}^{2} \mathrm{~cm}^{-4} \mathrm{~s}^{-1}\right)\end{array}$ \\
\hline $300^{\circ} \mathrm{C}$ & $\begin{array}{l}\text { None } \\
5 \times 10^{16}\end{array}$ & $\begin{array}{l}4.2 \times 10^{-6} \\
4.1 \times 10^{-7}\end{array}$ \\
& None & $9.1 \times 10^{-6}$ \\
$400^{\circ} \mathrm{C}$ & $5 \times 10^{16}$ & $2.1 \times 10^{-6}$ \\
& None & $7.9 \times 10^{-5}$ \\
$500^{\circ}$ & $5 \times 10^{15}$ & $2.4 \times 10^{-5}$ \\
& $1 \times 10^{16}$ & $1.6 \times 10^{-5}$ \\
& $5 \times 10^{16}$ & $4.2 \times 10^{-6}$ \\
\hline
\end{tabular}


The depth distribution or profile of the implanted tin in the iron substrate was assessed by means of RBS of $2 \mathrm{MeV}$ ${ }^{4} \mathrm{He}$ particles. The profile was determined after implantation, before the sample was exposed to oxygen at high temperature, and also after oxidation. Direct comparison between the two spectra of Fig. 3 shows that after oxidation the implanted tin is partly within the oxide film and partly in the metal-oxide interface; essentially, the tin preserves the same profile observed immediately after implantation. The RBS results give an initial hint about the effect of implanted $\mathrm{Sn}$ on the corrosion protection: during oxidation the implanted tin combines both with the iron of the substrate and with the available oxygen, forming a protective layer near the surface that reduces ionic migration.

The nature of this protective layer was investigated by CEMS. The measurements were carried out with a conventional, constant-acceleration spectrometer and sourves of ${ }^{57} \mathrm{Fe}$ in $\mathrm{Rh}$ and ${ }^{119} \mathrm{Sn}$ in $\mathrm{CaSnO}_{3}$ in a backscattering geometry. The samples were mounted on the backplate of a simple proportional counter through which helium (5\% methane) was allowed to flow.

In Fig. 4 the CEMS spectra of ${ }^{119} \mathrm{Sn}$ is shown for samples oxidized at different temperatures for typical times of 20 min. Immediately after implantation the spectrum has two
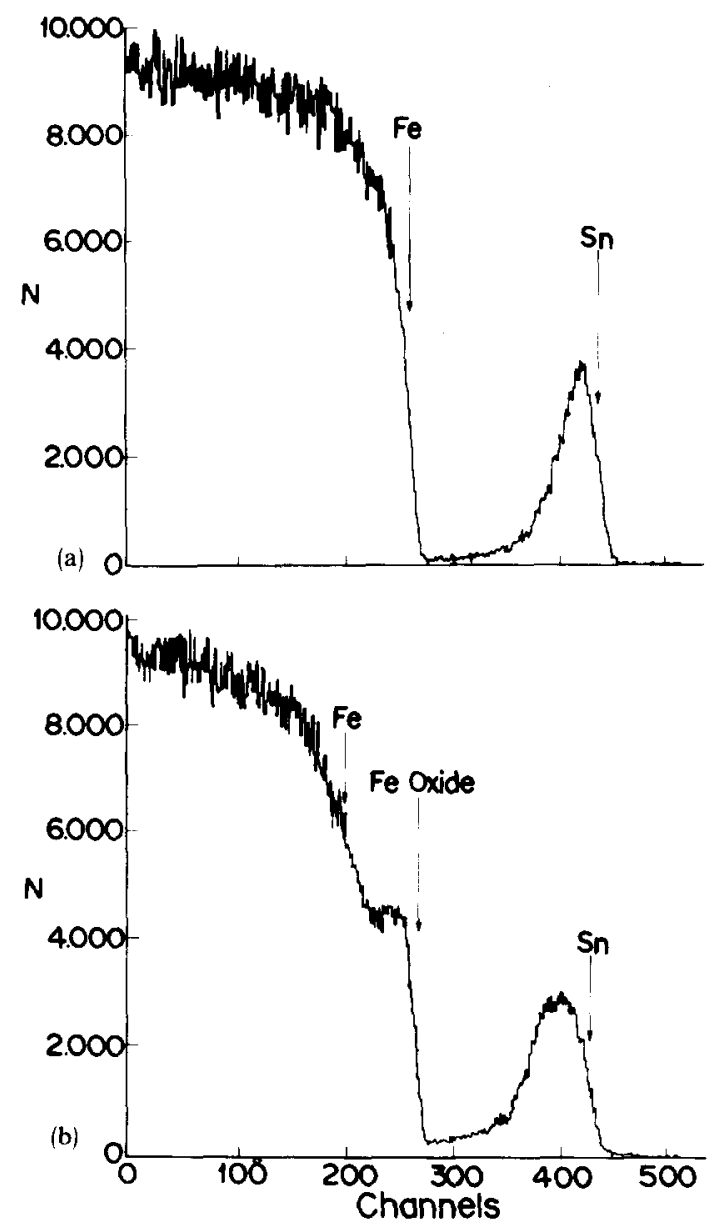

FIG. 3. Rutherford backscattering of 2-MeV ${ }^{4} \mathrm{He}$ particles in pure iron implanted with $5 \times 10^{16} \mathrm{Sn}^{+}$ions $\mathrm{cm}^{-2}$, before (a) and after (b) oxidation. The arrows indicate the position in the spectra of $\mathrm{Fe}$ and $\mathrm{Sn}$ at the surfaces.

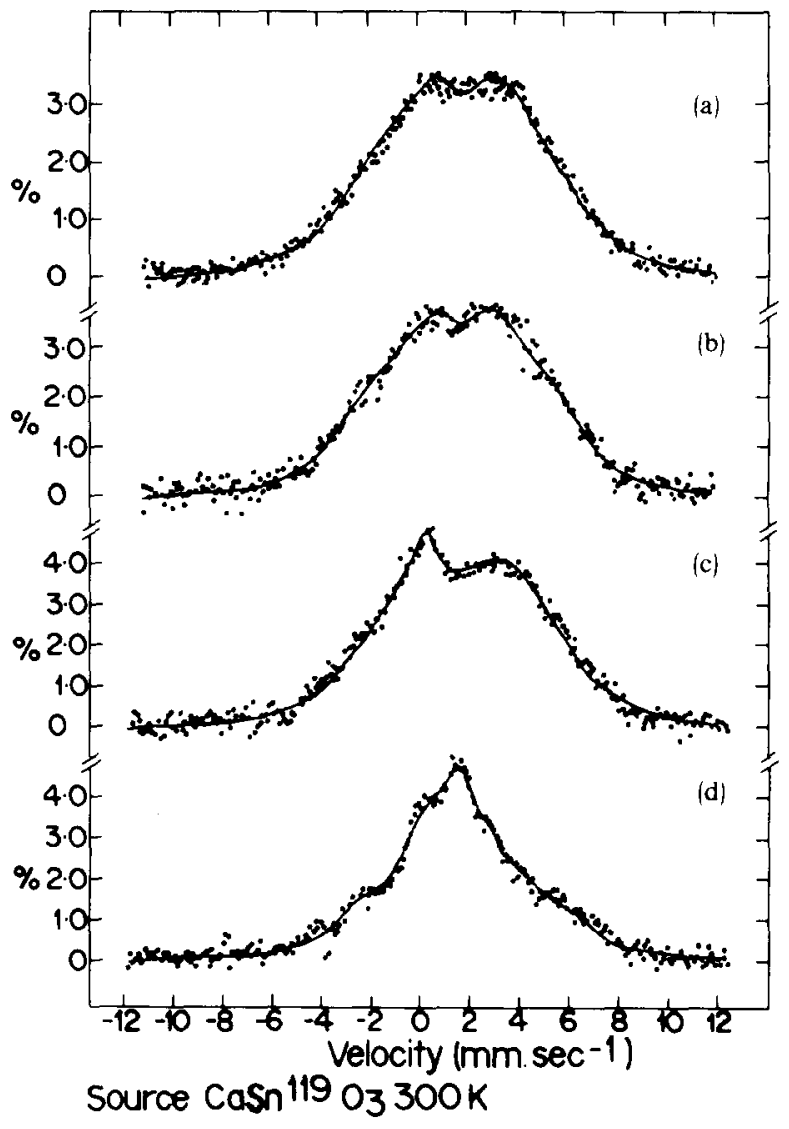

FIG. 4. ${ }^{119} \mathrm{Sn}$ conversion electrons Mössbauer scattering spectra, measured at room temperature, for iron implanted with $5 \times 10^{16} \mathrm{Sn}^{+}$ions $\mathrm{cm}^{2}$, oxidized at different temperatures for $20 \mathrm{~min}$ : (a) as implanted, (b) oxidized at $200^{\circ} \mathrm{C}$, (c) oxidized at $350^{\circ} \mathrm{C}$, and (d) oxidized at $500^{\circ} \mathrm{C}$

magnetic components [see Fig. 4(a) and Table II] which, by comparison with the works of Trumpy et al. ${ }^{13}$ and Vincze $e t$ al. ${ }^{14}$ are identified as the intermetallic compound $\mathrm{FeSn}_{2}$ and a solid solution $\mathrm{FeSn}$ at an average concentration of 4 at. \% of $\mathrm{Sn}$. The spectra corresponding to oxidation at higher temperatures reveal the formation of $\mathrm{SnO}_{2}$ at the surface at 350 ${ }^{\circ} \mathrm{C}$ and the formation of another intermetallic FeSn, as well

TABLE II. Parameters for the fittings of the ${ }^{119}$ Sn conversion electron Mössbauer scattering spectra of the implanted iron oxidized at different temperatures. In the last column the corresponding phases and compounds are given

\begin{tabular}{|c|c|c|c|c|c|}
\hline & $\begin{array}{l}H \\
\text { (kOe) }\end{array}$ & $\underset{\left(\mathrm{mm} \mathrm{s}^{-}\right.}{\delta}$ & $\frac{\Delta}{\left(\mathrm{mm} \mathrm{s}^{-1}\right.}$ & $\begin{array}{l}\text { Proportion } \\
1 \%)\end{array}$ & Phase \\
\hline As implanted & $\begin{array}{l}29.6 \\
66.0\end{array}$ & $\begin{array}{l}1.84 \\
1.41\end{array}$ & & $\begin{array}{l}66 \\
34\end{array}$ & $\begin{array}{l}\mathrm{FeSn}_{2} \\
\mathrm{FeSn}(4 \text { at. } \% \text { ) }\end{array}$ \\
\hline Oxidized & 30.1 & 1.92 & & 66 & $\mathrm{FeSn}_{2}$ \\
\hline $200^{\circ} \mathrm{C}$ & $\begin{array}{l}66.0 \\
\ldots\end{array}$ & $\begin{array}{l}1.48 \\
0.1\end{array}$ & & $\begin{array}{l}34 \\
17\end{array}$ & $\begin{array}{l}\mathrm{FeSn}(4 \text { at. \%) } \\
\mathrm{SnO}_{2}\end{array}$ \\
\hline Oxidized & 57.7 & 1.5 & & 37 & FeSn $(6$ at. $\%)$ \\
\hline $350^{\circ} \mathrm{C}$ & $\begin{array}{l}29.0 \\
\ldots \\
30.1\end{array}$ & $\begin{array}{l}1.97 \\
0.03 \\
1.96\end{array}$ & 0.2 & $\begin{array}{l}46 \\
14 \\
11\end{array}$ & $\begin{array}{l}\mathrm{FeSn}_{2} \\
\mathrm{SnO}_{2} \\
\mathrm{FeSn}_{2}\end{array}$ \\
\hline $\begin{array}{r}\text { Oxidized } \\
500^{\circ} \mathrm{C}\end{array}$ & $\begin{array}{l}58.2 \\
\cdots \\
49.7\end{array}$ & $\begin{array}{l}1.55 \\
1.6 \\
1.98\end{array}$ & & $\begin{array}{l}43 \\
22 \\
10\end{array}$ & $\begin{array}{l}\text { FeSn }(6 \text { at. \%) } \\
\text { FeSn }\end{array}$ \\
\hline
\end{tabular}




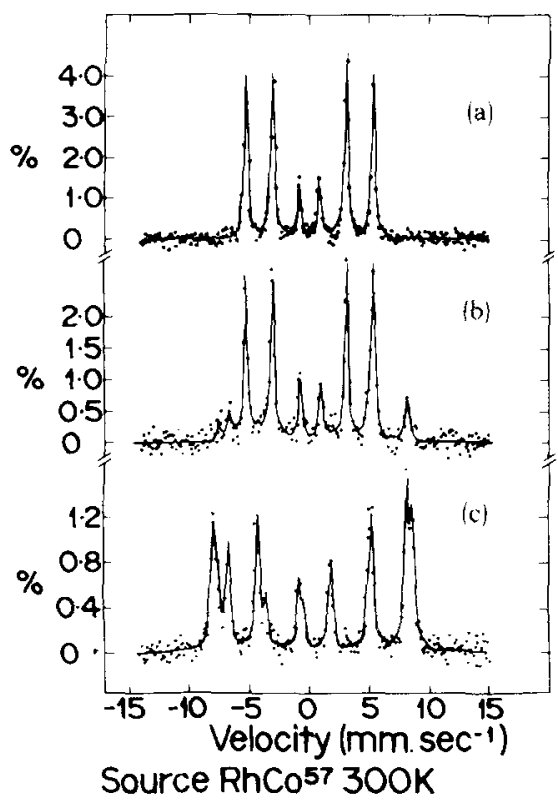

Source RhCo57 30OK

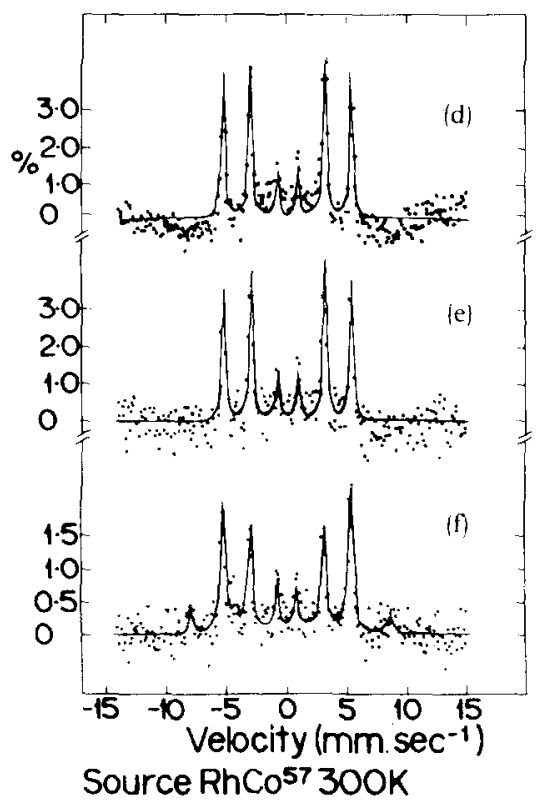

FIG. 5. ${ }^{57} \mathrm{Fe}$ conversion electrons Mössbauer scattering for unimplanted and implanted $\left(5 \times 10^{16} \mathrm{Sn}^{+}\right.$ions $\left.\mathrm{cm}^{2}\right)$ pure iron, oxidized at different temperatures. (a), (b), and (c): unimplanted iron oxidized at 200,350 , and $500^{\circ} \mathrm{C}$, respectively; (d), (e), and (f): implanted iron oxidized at 200,350 , and $500^{\circ} \mathrm{C}$, respectively. as $\mathrm{SnO}_{2}$, at $500^{\circ} \mathrm{C}$. The initially observed $\mathrm{FeSn}_{2}$ and $\mathrm{FeSn}$ are also present after oxidation at these temperatures, but the sample oxidized at $500^{\circ} \mathrm{C}$ has only $11 \%$ of $\mathrm{FeSn}_{2}$ whereas the proportion and average concentration of tin in $\mathrm{FeSn}$ rises to $43 \%$ and 6 at. \%, respectively.

The CEMS spectra of ${ }^{57} \mathrm{Fe}$ for the unimplanted and implanted $\left(5 \times 10^{16} \mathrm{Sn}^{+} \mathrm{cm}^{-2}\right)$ iron samples oxidized under the same conditions are shown in Fig. 5 and the parameters used to fit the curves are quoted in Table III. Fig. 5(a) shows the normal six-line spectrum of metallic iron. Exposure to oxygen at high temperatures produces two iron oxides $\mathrm{Fe}_{2} \mathrm{O}_{3}$ and $\mathrm{Fe}_{3} \mathrm{O}_{4}$ in the relative amounts quoted in Table III. $\mathrm{A}$ comparison between the CEMS of ${ }^{57} \mathrm{Fe}$ for the untreated and

TABLE III. Parameters for the fittings of the ${ }^{57} \mathrm{Fe}$ conversion electron Mössbauer scattering spectra of unimplanted and $\mathrm{Sn}^{+}$implanted pure iron.

\begin{tabular}{|c|c|c|c|c|c|}
\hline & $\begin{array}{c}H \\
(\mathrm{KOe})\end{array}$ & $\begin{array}{c}\delta \\
\left(\mathrm{mm} \mathrm{s}^{-1}\right)\end{array}$ & $\underset{\left(\mathrm{mm} \mathrm{s}^{-1}\right)}{\Delta}$ & $\begin{array}{c}\text { Proportion } \\
(\%)\end{array}$ & Phase \\
\hline $\begin{array}{c}\text { Unimplant } \\
\text { Oxidized } \\
200{ }^{\circ} \mathrm{C}\end{array}$ & 328.0 & 0.02 & 0.01 & 100 & $\mathrm{Fe}$ \\
\hline $\begin{array}{r}\text { Oxidized } \\
350^{\circ} \mathrm{C}\end{array}$ & $\begin{array}{l}328.9 \\
486.5 \\
458.5\end{array}$ & $\begin{array}{l}0.02 \\
0.29 \\
0.012\end{array}$ & $\begin{array}{l}0.01 \\
0.01 \\
0.77\end{array}$ & $\begin{array}{r}79 \\
8 \\
13\end{array}$ & $\begin{array}{l}\mathrm{Fe} \\
\mathrm{Fe}_{3} \mathrm{O}_{4}\end{array}$ \\
\hline $\begin{array}{r}\text { Oxidized } \\
500^{\circ} \mathrm{C}\end{array}$ & $\begin{array}{l}514 \\
488 \\
458\end{array}$ & $\begin{array}{l}0.39 \\
0.30 \\
0.01\end{array}$ & $\begin{array}{l}0.08 \\
0.01 \\
0.73\end{array}$ & $\begin{array}{l}46 \\
18 \\
36\end{array}$ & $\begin{array}{l}\mathrm{Fe}_{2} \mathrm{O}_{3} \\
\mathrm{Fe}_{3} \mathrm{O}_{4}\end{array}$ \\
\hline \multicolumn{6}{|c|}{$\begin{array}{l}\text { Implanted } \\
15 \times 10^{16} \mathrm{Sn} \text { ions } \mathrm{cm}^{-2}\end{array}$} \\
\hline $\begin{array}{l}\text { Oxidized } \\
220^{\circ} \mathrm{C}\end{array}$ & 328 & 0.02 & 0.01 & 100 & $\mathrm{Fe}$ \\
\hline $\begin{array}{r}\text { Oxidized } \\
350^{\circ} \mathrm{C}\end{array}$ & 328 & 0.03 & 0.01 & 100 & $\mathrm{Fe}$ \\
\hline $\begin{array}{r}\text { Oxidized } \\
500^{\circ} \mathrm{C}\end{array}$ & $\begin{array}{l}328 \\
511\end{array}$ & $\begin{array}{l}0.01 \\
0.42\end{array}$ & $\begin{array}{l}0.01 \\
0.10\end{array}$ & $\begin{array}{l}86 \\
14\end{array}$ & $\begin{array}{l}\mathrm{Fe} \\
\mathrm{Fe}_{2} \mathrm{O}_{3}\end{array}$ \\
\hline
\end{tabular}

treated samples shows that, as an effect of $\mathrm{Sn}^{+}$implantation, the rate of total oxidation and also the relative rates of formation of the different iron oxides are altered. So, for oxidation at $350^{\circ} \mathrm{C}$, the untreated sample formed $\mathrm{Fe}_{3} \mathrm{O}_{4}$ at the surface whereas the amount of oxide present in the treated one was not large enough to be seen in the CEMS spectrum. Moreover, at $500^{\circ} \mathrm{C}, 100 \%$ of the CEMS spectrum for the untreated sample is composed of $\mathrm{Fe}_{2} \mathrm{O}_{3}$ and $\mathrm{Fe}_{3} \mathrm{O}_{4}$ lines whereas the treated one shows only the lines corresponding to $\mathrm{Fe}_{2} \mathrm{O}_{3}$ with a relative area of $14 \%$ and the rest is metallic iron. These observations are consistent with Fig. 2 where the oxidation rate constant for the unimplanted sample at $300{ }^{\circ} \mathrm{C}$ and for the implanted sample at $500^{\circ} \mathrm{C}$ are the same.

The surfaces of the unimplanted and implanted samples were also observed with the SEM. Some of the SEM images are shown in Fig. 6; after oxidation for $20 \mathrm{~min}$ at $500^{\circ} \mathrm{C}$ the unimplanted sample is covered with a fine grained oxide film whereas the surface of the implanted sample has almost no oxide visible, allowing the metallic grain boundaries to show up after oxidation.

\section{DISCUSSION AND CONCLUSIONS}

The experimental results of the RBS and CEMS analyses described above indicate that the reduction in the oxidation rate constant of iron following the implantation of $\mathrm{Sn}^{+}$ ions is due to formation of a protective layer at the surface.

Moreover, CEMS analyses allowed us to identify the different phases forming this layer. It is apparent that for oxidation temperatures up to around $350^{\circ} \mathrm{C}$ or more, the main components at the surface layers are $\mathrm{FeSn}_{2}, \mathrm{FeSn}$ ( 4-6 at.\% of $\mathrm{Sn}$ ) and $\mathrm{SnO}_{2}$. For oxidation temperatures close to $500^{\circ} \mathrm{C}$ this picture is modified and although $\mathrm{FeSn}_{2}$ is still observed (in a smaller proportion) the main components are now a new intermetallic, FeSn, a higher proportion of the solid solution $\mathrm{FeSn}$ and $\mathrm{SnO}_{2}$.

So, perhaps different mechanisms are acting at different oxidation temperatures to inhibit the growth of the oxide 


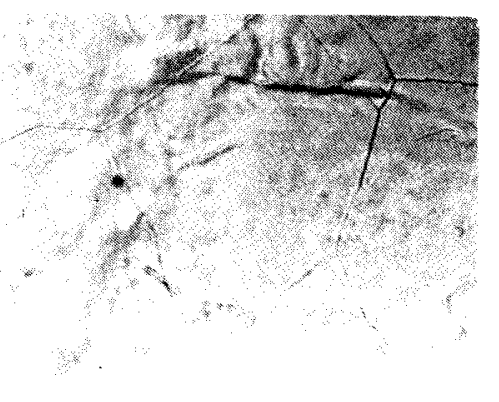

(a)

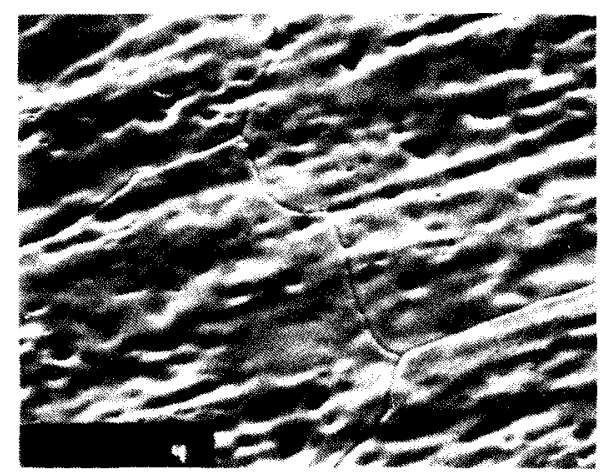

(c)

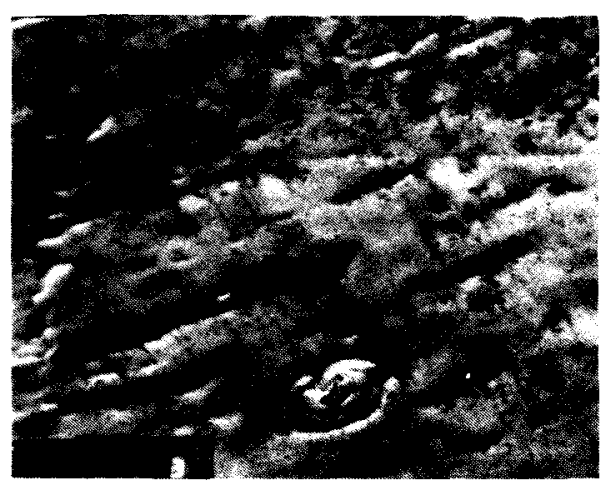

(b)

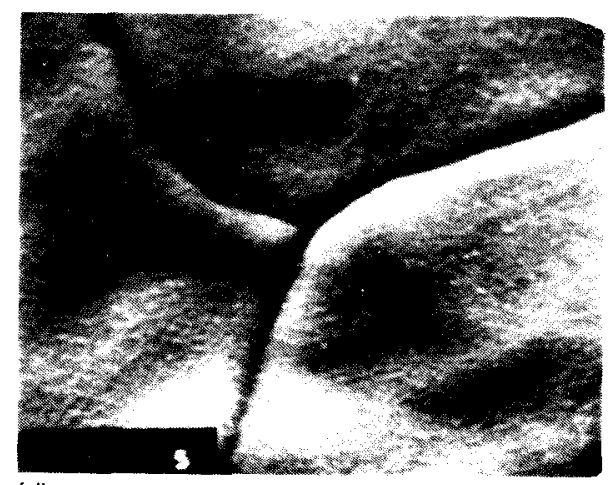

FIG. 6. Scanning electron microscope images of unimplanted and implanted iron oxidized at $500^{\circ} \mathrm{C}$ for $20 \mathrm{~min}$ : (a) optical microscope image of the electropolished sample before oxidation $(\times 400)$, (b) unimplanted sample oxidized $(\times 1000),(\mathrm{c})$ implanted sample oxidized $(\times 1000)$, and (d) implanted sample oxidized $(\times 6000)$ scale at the surface, since the protective layer has different compositions. But, at all measured temperatures, a parabolic rate law was roughly followed by the implanted samples. According to Wagner's classical theory, ${ }^{10}$ this is an indication that, at all temperatures, cation diffusion through the oxide is still the mechanism that dominates the oxidation process. ${ }^{11}$ The influence of ion implantation is to slow down the rate of ionic diffusion across the growing oxide scale.

At this stage it is important to understand how do the compounds formed at the surface layers influence the diffusion of cations. We do not know exactly the extent of development of the layer and whether or not it is complete (plain). From RBS analyses we know that, after oxidation, the implanted tin is partly within the oxide film and partly in the metal-oxide interface; consequently all the tin compounds participating on the protective layer should be in this region. The SEM images show [see Figs. 6(c) and 6(d)] a quite uniform external surface with only some flaws (holes). Energy dispersive analyses of $\mathrm{x}$-rays (EDAX) showed that the tin distribution on this surfaces is also very uniform, with no signs of accumulation at holes or grain boundaries.

Some understanding can be brought about if we compare these results with the existing knowledge about tinplating. The improved electrochemical corrosion resistance obtained by electro or thermal deposition of tin onto steels and iron exists because tin sacrificially protects iron and yet corrodes at a very low rate, and also as a consequence of the fact that the intermetallic compound $\mathrm{FeSn}_{2}$ is formed during the deposition process at the iron-tin interface. ${ }^{15,16}$ The function of $\mathrm{FeSn}_{2}$ is to act as a barrier between the active iron and tin members of the couple, reducing greatly the surface area of the iron that is sacrificially protected. $\mathrm{FeSn}_{2}$ is stable up to $496{ }^{\circ} \mathrm{C}$, at which temperature it decomposes into FeSn and
Sn. ${ }^{17}$ The ion implantation of iron with $\mathrm{Sn}^{+}$ions also produces a considerable amount of $\mathrm{FeSn}_{2}$ at the surface, as is revealed by the CEMS analyses. CEMS also shows that, for oxidation temperatures above $300^{\circ} \mathrm{C}$, part of the implanted tin is preferentially oxidized to form $\mathrm{SnO}_{2}$. Furthermore, oxidation at $500{ }^{\circ} \mathrm{C}$ partially decomposes $\mathrm{FeSn}_{2}$ at the surface and the CEMS spectrum shows the formation of FeSn and an enhancement in the proportion of free tin in solution in iron (in accordance with Ref. 17), as well as the already mentioned $\mathrm{SnO}_{2}$. So, there are similarities in the compositions at surfaces treated by ion implantation of tin and tinplating. Even considering that implanted tin is continuously distributed through the iron substrate, without a well defined interface, it is possible to understand its action as an inhibitor to the corrosion of iron, by the formation of a protective layer of $\mathrm{SnO}_{2}$ and $\mathrm{FeSn}_{2}$ and also FeSn (at higher oxidation temperatures). It would be very useful to know whether or not the $\mathrm{FeSn}_{2}$ layer, in particular, is complete. However, this is not feasible on the basis of the available experimental results.

Further work is in progress to investigate the extent of development and depth distribution in the protective layer as well as its influence on the main diffusing species.

\section{ACKNOWLEDGMENTS}

This work was performed in the Atomic Energy Research Establishment at Harwell under a grant of Conselho Nacional de Desenvolvimento Científico e Tecnológico (CNPq). The author wishes to thank Doctor G. Dearnaley for making available all the research facilities of the IonCrystal Interactions Group at Harwell and Doctor G. Longworth and L. W. Becker for their help with running and analyzing the CEMS measurements. 
'U. Bernabai, M. Cavallini, G. Bombara, G. Dearnaley, and M. A. Wilkins, Corros. Sci. 20, 19 (1980).

${ }^{2}$ R. A. Collins, S. Muhl, and G. Dearnaley, J. Phys. F 9, 1245 (1979).

${ }^{3}$ L. G. Svendsen, Corros. Sci. 20, 63 (1980).

${ }^{4}$ I. J. R. Baumvol, R. E. J. Watkins, G. Longworth, and G. Dearnaley, Proceedings of the LEIB-II Conference, The Institute of Physics Conference Series 54, 201 (1980).

${ }^{5}$ R. E. Watkins (private communication).

${ }^{6} \mathrm{M}$. Kerridge, Proc. Phys. Soc. 68, 400 (1955).

${ }^{7}$ W. K. Chu, J. W. Mayer, M. A. Nicolet, T. M. Buck, G. Amsel, and F. Eisen, Thin Solid Films 17, 1 (1973).

${ }^{8}$ R. J. Hussey and M. Cohen, Corros. Sci. 11, 713 (1971).
${ }^{9}$ D. A. Channin and M. J. Graham, Corros. Sci. 12, 271 (1972).

'"C. Wagner, Z. Physik. Chem. B21, 25 (1933).

"P. Kofstad, High Temperature Oxidation of Metals (Wiley, New York, 1966).

${ }^{12}$ J. C. Scully, The Fundamentals of Corrosion (Pergamon, Oxford, 1975).

${ }^{1.3}$ G. Trumpy, E. Both, and P. Lecocq, Phys. Rev. B 2, 3477 (1970).

${ }^{14}$ I. Vincze and A. T. Aldred, Phys. Rev. B 9, 3845 (1974).

${ }^{15} \mathrm{H}$. Leidheiser, Jr., The Corrosion of Copper, Tin and Their Alloys (Wiley, New York, 1971).

${ }^{16} \mathrm{H}$. E. Biber, J. Electrochem. Soc. 113, 362 (1966).

${ }^{17} \mathrm{M}$. Hausen, Constitution of Binary Alloys (McGraw-Hill, New York, 1958). 